\title{
Gastrointestinal nematodes of dairy goats, anthelmintic resistance and practices of parasite control in Northern Italy
}

\author{
Sergio Aurelio Zanzani ${ }^{1}$, Alessia Libera Gazzonis ${ }^{1}$, Annarita Di Cerbo ${ }^{1}$, Marian Varady ${ }^{2}$ and Maria Teresa Manfredi ${ }^{*}$
}

\begin{abstract}
Background: Gastrointestinal nematodes (GINs) are one of the main constraints to ruminant production worldwide. Anthelmintic resistance (AR) has been reported in goats throughout Europe, yet little is known about the AR status in Italy. The aims of the study were: i) determine the frequency of AR in GINs in goat flocks in Northern Italy, Italy, ii) survey goat farmers on the current practices of parasite control, iii) update the species composition of the gastrointestinal helminthofauna. Thirty three flocks were enrolled and 1288 individual fecal samples were collected. Based on the egg per gram (EPG), 15 flocks were selected to evaluate the presence of AR in GINs with the Fecal Egg Count Reduction Test (FECRT). A questionnaire surveyed 110 dairy goat farmers to acquire information about farm management and drenching practices against GINs. Further, the gastrointestinal tracts of 42 goats were analyzed.

Results: The FECRs indicated that five of the 15 flocks had problems of AR, which was identified in all two of the anthelmintic classes tested. Resistance and suspected resistance was found in $40 \%$ of the flocks selected for AR testing that were treated with benzimidazoles while $20 \%$ of the flocks treated with eprinomectin had resistant GINs.

Teladorsagia/Trichostrongylus $\mathrm{L} 3$ were isolated from the post-treatment coprocultures of all flocks with resistance but not from the flock with suspected oxfendazole resistance. Treatments against helminths were performed once annually in $73.63 \%$ of the flocks, but $20.00 \%$ of farmers declared not regularly treating their goats every year. Annual treatments usually occurred in autumn or winter at dose rate for sheep. Te. circumcincta, H. contortus, Tr. colubriformis, Skrjabinema caprae and Oesophagostomum venulosum were the most abundant and prevalent species of the gastrointestinal tract.

Conclusions: Strategies to prevent the development of AR should be widely adopted in Northern Italy. Further, farmers and practitioners should be educated about the importance of using the correct dose rates in goats. In addition, the presence of highly pathogenic GINs coupled with high worm burden in all sector of gastrointestinal tract and the prevalence values further suggest that improved diagnosis and active surveillance of GINs infection is needed.
\end{abstract}

Keywords: Parasites, Gastrointestinal nematodes, Anthelmintic resistance, Goat, Italy

\section{Background}

Gastrointestinal nematodes (GINs) remain one of the main constraints to ruminant production, since they can causing reduction in skeletal growth, live-weight gain and in milk yield [1,2]. GINs infection is of economic importance also in goat farming worldwide and the peculiarities of goat-nematode interactions could affect the control strategies of GINs. In particular, goats can be significantly more heavily infected than sheep and both

\footnotetext{
* Correspondence: mariateresa.manfredi@unimi.it

${ }^{1}$ Department of Veterinary Science and Public Health, Università degli Studi di Milano, Milan, Italy

Full list of author information is available at the end of the article
}

the acquisition and expression of immune responses against GINs are less efficient in goats than sheep [3]. Further, the control of GINs infection in goats is still largely based on use of drugs at regular intervals and currently is made more complicated by the presence of resistant nematodes to one or more type of drugs. The phenomenon of anthelmintic resistance (AR) is spread in many countries with differences in prevalence and some data showed that GINs develop anthelmintic resistance more rapidly in goats $[4,5]$. A few recent studies have examined the gastrointestinal parasites of goats [6,7], but none have described the control practices used on dairy-goat farms in Northern Italy and especially in Lombardy. Anthelmintic 
resistance (AR) against benzimidazoles has previously been reported in this area but is considered rare [8]. Knowledge of the presence of this phenomenon and of the control practices that are normally employed by farmers could be useful for improving both the management of gastrointestinal parasites and the milk production of grazing goats in marginal or mountain areas. Nevertheless, knowledge of the specific composition of the gastrointestinal helminthofauna can also supply valuable information for parasite control. The main aim of this study was to evaluate the presence of AR in the gastrointestinal nematodes of various breeds of dairy goats in Northern Italy by the fecal egg count reduction test (FECRT) and to determine which species could be implicated in resistance using larval cultures. A secondary aim was to survey goat farmers on the current practices of parasite control on farms in Northern Italy. Another goal was to update the species composition of the gastrointestinal helminthofauna by identifying the adult nematodes recovered from gastrointestinal tracts.

\section{Methods}

A survey was performed with a questionnaire from November 2010 to June 2011 in Lombardy, a region of Northern Italy $\left(45^{\circ} 40^{\prime} \mathrm{N}, 9^{\circ} 30^{\prime} \mathrm{E}\right)$. Members of SATA, a regional association offering zootechnical and veterinarian support to breeders, were involved in the study. The majority of surveyed farms were in the areas of Northern Italy most suitable for goat breeding.

All animal procedures used in this study were approved by the Milan University Institutional Animal Care and Use Committee.

\section{Evaluation of AR}

\section{Fecal egg count reduction test (FECRT)}

Individual fecal samples were collected from the rectums of 1288 dairy goats from 33 flocks. All animals were older than two years of age. The parasitological analyses used a modified McMaster method [9,10], with $40.5 \mathrm{ml}$ of a sodium nitrate and sucrose-based flotation solution (specific gravity $=1.30$ ) and $4.5 \mathrm{~g}$ of feces. The numbers of eggs per gram (EPG) were calculated. Based on the EPGs, 15 flocks were selected to evaluate in vivo the presence of AR in GINs with the FECRT, in accordance with the guidelines of the World Association for the Advancement of Veterinary Parasitology (WAAVP) [11,12].

Benzimidazoles and probenzimidazoles (BZs) and macrocyclic lactones (MLs) were the classes of anthelmintic selected for evaluation in this survey based on the information obtained from the questionnaire. Albendazole (ABZ) $(7.5 \mathrm{mg} / \mathrm{kg}$ body weight (bw)), oxfendazole (OFZ) (10 $\mathrm{mg} / \mathrm{kg} \mathrm{bw})$, febantel (10 $\mathrm{mg} / \mathrm{kg}$ bw) and netobimin (15 mg/kg bw) were tested in ten flocks. Ivermectin (IVM) and moxidectin $(\mathrm{MOX})$ at $0.4 \mathrm{mg} / \mathrm{kg}$ were administrated to goats of one and two flocks, respectively. Finally, eprinomectin (EPM) at an extra-label dose of $1 \mathrm{mg} / \mathrm{kg}$ bw was tested in two flocks. All drugs were orally dosed except EPM, which was applied with a pour-on formulation. The dose rates of the anthelmintics were twice as high as those for sheep or cattle. The body weight of the visually heaviest goat of each flock was estimated to determine the anthelmintic dose rate. The number of dosed animals in each flock, based on the recommendations provided by Coles et al. [11], varied from 20 to 32 goats depending on flock size.

Individual fecal samples were collected on the day of treatment (T1). T1 mean EPG and standard deviation were calculated for each flock. FECRTs were performed only on goats with EPGs $\geq 150$ at $\mathrm{T} 1$. Individual post-treatment fecal samples (T2) were collected after 8-10 days from goats treated with BZs and after 14-17 days from goats treated with MLs. The fecal egg count reduction (FECR) was calculated with the formula proposed by Cabaret and Berrag [13], in which each host serves as its own control:

$$
\operatorname{FECR}=(1 / n) \Sigma\left(100 x\left(1-\left[T_{i 2}-T_{i 1}\right]\right)\right)
$$

where $T_{i 2}$ is post-treatment and $T_{i 1}$ is pre-treatment EPG in host $i$ from a total of $n$ hosts. The tested population of nematodes was classified as resistant when the FECR was $<95 \%$ and the lower limit of the $95 \%$ confidence interval (CI) was $<90 \%$ or as "suspected resistant" when the FECR was $<95 \%$ or the lower limit of the $95 \%$ CI was $<90 \%$ [11].

\section{Larval cultures}

Pre- and post-treatment larval cultures were performed from pooled fecal samples for each flock; pools were composed with feces collected from each animal of the group. The feces sampled at T1 and T2 were incubated for 10 days at $25^{\circ} \mathrm{C}$ in a large vessel, ensuring adequate moisture (50$80 \%$ ), and third-stage larvae (L3) were recovered from the coprocultures by a Baermann technique [9]. The first 100 randomly selected L3 of each pool were then examined with a light microscope (Axioscope 2, Zeiss) and were identified to the generic level as Teladorsagia/Trichostrongylus, Oesophagostomum/Chabertia, Haemonchus, Nematodirus, Bunostomum and Cooperia, according to MAFF [9] and van Wyk et al. [14]. When fewer than $100 \mathrm{~L} 3$ were isolated from a pool, the percentage of larval type was calculated on the basis of the counted L3.

\section{Farm questionnaire}

A questionnaire surveyed 110 dairy goat farmers from 51, 43, 10 and six farms from eastern (Bergamo (BG) and Brescia (BS) provinces), western (Como (CO), Lecco (LC) and Varese (VA) provinces), northern (Sondrio (SO) province) and southern (Pavia (PV) province) areas of 
Lombardy, respectively. Each farmer was asked about their farm management, including the presence and dimensions of pastures, demography and breed of goats, the presence of other species on the farm (e.g. cattle) and drenching practices against GINs, such as treatment times, frequency, products and dosages of anthelmintic drugs. Farm veterinarians contributed to answering these last questions.

\section{Composition of gastrointestinal helminthofaunas}

The gastrointestinal tracts of two or three goats from the 15 flocks previously selected to evaluate the presence of AR were collected at abattoirs. The species composition and abundance of abomasal and intestinal nematodes of 42 goats were analyzed. Abomasa and small and large intestines were examined separately; they were opened and the contents were filtered through metallic sieves to collect adult helminths [9]. Ten percent of the content was examined with a stereomicroscope, and the extracted worms were counted. Cleared male worms were identified according to established descriptions [15-20]. The nomenclature used for Ostertagiinae was that proposed by Drózdz [15] and Durette-Desset [21]. The numbers of nematodes in the content fractions were adjusted to the total volumes from the abomasa or intestines. The total number of nematodes (males and females) and the number of individuals of each species based on the taxonomy of adult male worms were recorded. Epidemiological indexes, mean abundance $(\mathrm{A})$ and prevalence $(\mathrm{P})$, were calculated for each species of helminth when possible [22]. The helminth community structure was examined by the importance value, I, that was calculated for each of the helminth species according to Thul et al. [23].

\section{Results}

\section{Evaluation of AR}

Adult goats of the 15 flocks selected for testing AR had a mean pre-treatment EPG of $426.93( \pm 249.11)$ (Table 1$)$. Baermannized L3 isolated from pre-treatment pools of individual fecal samples showed that Teladorsagia/Trichostrongylus were the most common GINs in the study area: Teladorsagia/Trichostrongylus L3 were recovered from 13 of the 15 flocks (86.6\%) and were the most prevalent GINs in eight of the 13 flocks (61.5\%) infected with these worms. Oesophagostomum/Chabertia and Haemonchus L3 were recovered from 11 (73.3\%) and nine (60\%) flocks, respectively, and Haemonchus was the most prevalent GIN in six of the nine flocks (66.6\%) infected with this species. Bunostomum, isolated from five flocks (33.3\%), was the most prevalent GIN in flock 11 . According to Table 1 Nematodirus L3 were isolated only from flock 3, and Cooperia L3 were not found in any flock.

The percentages of the FECRs and the 95\% confidence intervals of the fifteen investigated flocks are shown in Table 2. The FECRs after treatment indicated that 4 cases and 1 doubt of the 15 flocks (33.33\%) had problems of $\mathrm{AR}$, which was identified in the tested anthelmintic classes. One of the three flocks dewormed with ABZ had a post-treatment FECR fitting the criteria for resistance proposed by Coles [11]: the FECR was $81.11 \%$ and the lower 95\% CI limit was 69\%. One of the two flocks dewormed with OFZ was classified as "suspected resistant" (FECR = 95.17, lower 95\% CI limit=88\%). The FECR was $100 \%$ in all flocks treated with netobimin, demonstrating the complete efficacy of this drug. Both flocks treated with febantel had resistant worms, with very low FECRs $(40.52$ and $76.01 \%$, respectively) and lower 95\% CI limits (58\% and $-3 \%$, respectively). ML treatments were effective in four of five flocks; one of the two flocks treated with EPM was classified as resistant, having a FECR of $87.43 \%$ and a lower $95 \%$ CI limit of $76 \%$. All areas of Northern Italy had flocks with FECRs less than $100 \%$. The flocks with resistance or suspected resistance were all located in the eastern provinces. Teladorsagia/Trichostrongylus L3 were isolated from the post-treatment coprocultures of all flocks with resistance but not from the flock with "suspected" OFZ resistance. A low percentage of Haemonchus larvae (25\%) were isolated from the coproculture of the flock with EPM resistance (Table 2).

\section{Farm questionnaire}

The questionnaire survey indicated that $42.73 \%$ (47/110) of the goat farms practiced grazing, and the majority of farms with pastures $(60.5 \%)$ were in the western area. Pastures had a mean area of 11.63 ha (range, 1-50 ha) and altitudes from 200 to $1500 \mathrm{~m}$ a.s.l. Goats usually grazed from March or May to October or November during the day (or at night in the hottest months) and were kept in the fold at night (or day in the hottest months), depending on the region. Intensive breeding was the most common system in farms from southern (100\%) or eastern (90.2\%) areas, whereas only $55.8 \%$ or $50 \%$ of farms from western or northern areas, respectively, had this type of farming. Farms in the eastern and northern areas had the largest mean flock sizes ( 84.65 and 100.85 , respectively); these farms also had the highest number of does (Table 3). Only one breed of goat was farmed in $89.10 \%$ (98/110) of the flocks. Eleven of 110 (10\%) farms had does belonging to autochthonous breeds (Orobica, Nera di Verzasca, Bionda dell'Adamello and Frisa Valtellinese), but only five farms raised only one these breeds. The autochthonous breeds were raised on farms of northern (3/11), eastern (5/11) and western (3/11) Lombardy according to the geographical area from which they originated. A large number of farmers (49.10\%) confirmed maintaining other species (cattle or sheep) on their farms, but generally in low numbers. Goat farms were mainly specialized for cheese production. The percentage of farms producing milk for cheese varied from 70\% in northern areas to $100 \%$ in southern areas (Table 3). 
Table 1 Mean eggs per gram (EPG) from fecal egg counts (FEC) and third-stage larvae identified in the goats of flocks selected for testing for anthelmintic resistance

\begin{tabular}{|c|c|c|c|c|c|c|c|c|c|}
\hline \multirow[t]{2}{*}{ Flock no. } & \multirow[t]{2}{*}{ Province* } & \multirow[t]{2}{*}{ Area } & \multicolumn{2}{|c|}{ Pre-treatment FEC } & \multicolumn{5}{|c|}{ Pre-treatment coproculture } \\
\hline & & & Mean EPG & $\pm \mathrm{SD}^{\circ}$ & Telad/Trich & Oesop/Chab & Haem & Nemat & Bunost \\
\hline 1 & BS & $\mathrm{E}$ & 248 & 100 & 96 & 4 & 0 & 0 & 0 \\
\hline 2 & BS & $\mathrm{E}$ & 1317 & 1040 & 0 & 3 & 97 & 0 & 0 \\
\hline 3 & BS & $\mathrm{E}$ & 250 & 62 & 81 & 0 & 0 & 9 & 10 \\
\hline 4 & BS & E & 424 & 294 & 82 & 5 & 13 & 0 & 0 \\
\hline 5 & BG & E & 307 & 397 & 78 & 17 & 5 & 0 & 0 \\
\hline 6 & $B G$ & E & 720 & 484 & 30 & 27 & 43 & 0 & 0 \\
\hline 7 & $B G$ & $E$ & 261 & 110 & 81 & 19 & 0 & 0 & 0 \\
\hline 8 & $B G$ & $\mathrm{E}$ & 367 & 245 & 84 & 0 & 0 & 0 & 16 \\
\hline 9 & $B G$ & $\mathrm{E}$ & 468 & 264 & 32 & 29 & 39 & 0 & 0 \\
\hline 10 & $B G$ & E & 289 & 225 & 92 & 4 & 0 & 0 & 4 \\
\hline 11 & VA & W & 312 & 144 & 29 & 0 & 0 & 0 & 71 \\
\hline 12 & VA & W & 494 & 350 & 0 & 0 & 100 & 0 & 0 \\
\hline 13 & VA & W & 400 & 397 & 24 & 7 & 69 & 0 & 0 \\
\hline 14 & VA & W & 218 & 62 & 20 & 4 & 76 & 0 & 0 \\
\hline 15 & $\mathrm{SO}$ & $\mathrm{N}$ & 329 & 85 & 77 & 5 & 12 & 0 & 6 \\
\hline
\end{tabular}

*BS = Brescia, $B G=$ Bergamo, $V A=$ Varese, $S O=$ Sondrio $^{\circ}=$ standard deviation, Telad $/$ Trich $=$ Teladorsagia/Trichostrongylus, Oesop $/$ Chab $=$ Oesophagostomum $/$ Chabertia Haem $=$ Haemonchus, Nemat $=$ Nematodirus, Bunost $=$ Bunostomum .

Table 2 Fecal egg count reduction (FECR), 95\% confidence intervals (CI) and third-stage larvae (L3) identified in post-treatment coprocultures in selected goat flocks

\begin{tabular}{|c|c|c|c|c|c|c|c|}
\hline \multirow{2}{*}{$\begin{array}{l}\text { Anthelmintic } \\
\text { class }\end{array}$} & \multirow[t]{2}{*}{ Drug } & \multirow[t]{2}{*}{ Flock no. } & \multirow[t]{2}{*}{ FECR (\%) } & \multirow[t]{2}{*}{$95 \% \mathrm{Cl}$} & \multirow[t]{2}{*}{ Status } & \multicolumn{2}{|l|}{ Post-treatment coproculture } \\
\hline & & & & & & L3 type (\%) & No. L3 seen \\
\hline \multirow[t]{10}{*}{ BZs } & $A B Z$ & 1 & 100 & $\circ$ & S & & 0 \\
\hline & OFZ & 3 & 100 & $\circ$ & S & & 0 \\
\hline & OFZ & 4 & 95.17 & $88-100$ & $S R^{* *}$ & & 0 \\
\hline & $A B Z$ & 5 & 81.11 & $69-94$ & $\mathrm{R}^{*}$ & Teladorsagia/Trichostrongylus (100) & 23 \\
\hline & $A B Z$ & 6 & 100 & $\circ$ & S & & 0 \\
\hline & Febantel & 7 & 76.01 & $58-94$ & $R^{*}$ & Teladorsagia/Trichostrongylus (100) & 15 \\
\hline & Febantel & 8 & 40.52 & -3 to 84 & $\mathrm{R}^{*}$ & Teladorsagia/Trichostrongylus (100) & 38 \\
\hline & Netobimin & 11 & 100 & $\circ$ & $S$ & & 0 \\
\hline & Netobimin & 12 & 100 & $\circ$ & S & & 0 \\
\hline & Netobimin & 13 & 100 & $\circ$ & S & & 0 \\
\hline \multirow[t]{5}{*}{ MLs } & IVM & 10 & 100 & $\circ$ & S & & 0 \\
\hline & MOX & 14 & 98.82 & $97-100$ & S & & 0 \\
\hline & MOX & 15 & 98.57 & $96-100$ & S & & 0 \\
\hline & EPM & 2 & 99.32 & $98-100$ & S & & 0 \\
\hline & EPM & 9 & 87.43 & $76-99$ & $\mathrm{R}^{*}$ & Teladorsagia/Trichostrongylus (75), Haemonchus (25) & 16 \\
\hline
\end{tabular}

$B Z s$, Benzimidazoles and probenzimidazoles; $M L s$, Macrocyclic lactones.

$A B Z$, Albendazole; OFZ, Oxfendazole; IVM, Ivermectin; MOX, Moxidectin; EPM, Eprinomectin.

$\mathrm{S}$, susceptible.

*resistant (R) flock: FECR <95\% AND lower 95\% Cl limit <90\%.

** suspected resistant (SR) flock: FECR <95\% OR lower 95\% Cl limit <90\%.

${ }^{\circ} 95 \% \mathrm{Cl}$ not calculated because the reduction was $100 \%$. 
Table 3 Characteristics of goat farms and flock demographics

\begin{tabular}{|c|c|c|c|c|c|c|c|c|}
\hline \multirow[t]{2}{*}{ Location of farm } & \multirow{2}{*}{$\begin{array}{l}\text { No. farms } \\
\text { surveyed }\end{array}$} & \multicolumn{3}{|c|}{ Breeding system (\% of farms) } & \multirow[t]{2}{*}{ Pasture (\% of farms) } & \multirow{2}{*}{$\begin{array}{c}\text { Mean flock size } \\
\text { (Does, range) }\end{array}$} & \multirow[t]{2}{*}{ Main breeds } & \multirow{2}{*}{$\begin{array}{c}\text { Production of } \\
\text { cheese }(\% \text { of farms }\end{array}$} \\
\hline & & $E^{*}$ & $\mathrm{SE}^{\circ}$ & $1^{\S}$ & & & & \\
\hline \multirow[t]{3}{*}{ Eastern area } & 51 & 5.8 & 1.9 & 90.2 & 31.4 & $84.65(18-840)$ & Alpine & 82.35 \\
\hline & & & & & & & Saanen & \\
\hline & & & & & & & Orobica & \\
\hline \multirow[t]{2}{*}{ Northern area } & 10 & 0 & 30 & 50 & 40 & $100.85(21-190)$ & Alpine & 70 \\
\hline & & & & & & & Frisa Valtellinese & \\
\hline \multirow[t]{3}{*}{ Western area } & 43 & 34.8 & 9.3 & 55.8 & 60.5 & $40.97(4-156)$ & Alpine & 86 \\
\hline & & & & & & & Saanen & \\
\hline & & & & & & & Nera di Verzasca & \\
\hline Southern area & 6 & 0 & 0 & 100 & 16.6 & $39.20(7-93)$ & Alpine & 100 \\
\hline
\end{tabular}

* = extensive, goats are free to graze and browse all over the year.

${ }^{\circ}=$ semi-extensive, goats are kept in the fold during winter before the kidding period (January to March) and from March to November they are free to graze and browse.

$\S=$ intensive, goats are reared indoor all over the year.

Treatments against helminths were performed once annually in $73.63 \%(81 / 110)$ of the flocks, but $20.00 \%$ $(22 / 110)$ of farmers declared not regularly treating their goats every year. No differences in frequency of treatments were detected depending on the breeding system and reared breeds. Annual treatments usually occurred in autumn or winter (November to January), depending on the farm and particularly on the dry status of does. A few flocks received an additional treatment in summer when necessary, and a low percentage of farms $(2.72 \%)$ regularly administered two treatments. The choice of anthelmintic varied among the farms but was dominated by BZs $(87.27 \%)$; only $2.73 \%(3 / 110)$ of farmers treated their flocks with MLs. Anthelmintics were not rotated on any of the farms. In $89.09 \%$ (98/110) of the flocks, anthelmintic dose rates were calculated on the basis of the visually estimated body weight of the goat that appeared heaviest. The dose rate for sheep was used to treat the goats in all these flocks. Eleven of the 110 farmers $(10 \%)$ did not indicate the dose rate used in their flocks. Annual treatments were usually done without any parasitological analyses, which were only performed on particular occasions (Table 4).

\section{Composition of gastrointestinal helminthofauna}

All necropsied goats were infected by GINs $(\mathrm{P}=100 \%)$. T. circumcincta was the most abundant (mean $\mathrm{A}=558.62$ ) and most frequent $(\mathrm{P}=73 \%)$ abomasal parasite in all studied goats, followed by $H$. contortus (mean $\mathrm{A}=69, \mathrm{P}=46 \%$ ). Other abomasal species belonging to the subfamily Ostertagiinae (Ostertagia ostertagi, Os. leptospicularis, Spiculopteragia spiculoptera morph spiculoptera, Te. pinnata and Te. trifurcata) were also present but with low abundances and prevalences (Table 5). Tr. colubriformis and N. lanceolatus (mean $\mathrm{A}=444.31$ and 41.21, respectively) were the dominant species in the small intestine, whereas
Table 4 Responses of $\mathbf{1 1 0}$ goat farmers to a questionnaire about practices of gastrointestinal-nematode control in dairy goats

Factor Percentage (n)

Control of gastrointestinal

parasites

\begin{tabular}{|c|c|c|c|}
\hline Pasture management & \multicolumn{3}{|l|}{0} \\
\hline Anthelmintic treatment & \multicolumn{3}{|l|}{$100 \%$} \\
\hline \multicolumn{4}{|l|}{ Coprological analysis } \\
\hline Before treatment & \multicolumn{3}{|l|}{0} \\
\hline Post treatment & \multicolumn{3}{|l|}{0} \\
\hline \multicolumn{4}{|l|}{ Anthelmintic used } \\
\hline \multirow{5}{*}{$\begin{array}{l}\text { Benzimidazoles and } \\
\text { probenzimidazoles }\end{array}$} & \multirow[t]{5}{*}{$87.27 \%(96)$} & Albendazole & $25.45 \%(28)$ \\
\hline & & Febendazole & $25.45 \%(28)$ \\
\hline & & Oxfendazole & $8.18 \%(9)$ \\
\hline & & Netobimin & $23.64 \%(26)$ \\
\hline & & Febantel & $4.55 \%(5)$ \\
\hline \multirow[t]{3}{*}{ Macrocyclic lactones } & \multirow[t]{3}{*}{$2.73 \%(3)$} & Ivermectin & $0.91 \%(1)$ \\
\hline & & Moxidectin & $0.91 \%(1)$ \\
\hline & & Eprinomectin & $0.91 \%(1)$ \\
\hline $\mathrm{Nd}^{*}$ & $10.00 \%(11)$ & - & - \\
\hline \multicolumn{4}{|l|}{ Frequency of treatment/year } \\
\hline 0 & \multicolumn{3}{|l|}{$20.00 \%$} \\
\hline 1 & \multicolumn{3}{|l|}{$73.63 \%$} \\
\hline 2 & \multicolumn{3}{|l|}{$2.72 \%$} \\
\hline $\mathrm{Nd}$ & \multicolumn{3}{|l|}{$3.63 \%$} \\
\hline \multicolumn{4}{|l|}{ Time of treatment } \\
\hline Autumn/winter & \multicolumn{3}{|l|}{$82 \%$} \\
\hline Summer & \multicolumn{3}{|l|}{$9 \%$} \\
\hline Autumn/winter + summer & \multicolumn{3}{|l|}{$9 \%$} \\
\hline
\end{tabular}

*not done 
Table 5 Mean abundance (A), prevalence (P), importance value (I) and location of gastrointestinal nematodes recovered in dairy goats

\begin{tabular}{|c|c|c|c|c|c|}
\hline \multirow[t]{2}{*}{ Nematode species } & \multirow[t]{2}{*}{$A\left(S D^{\circ}\right)$} & \multirow[t]{2}{*}{ Min-Max } & \multirow[t]{2}{*}{$\mathrm{P}(\%)$} & \multicolumn{2}{|c|}{1} \\
\hline & & & & Values & Categories $^{\S}$ \\
\hline \multicolumn{6}{|l|}{ Abomasum } \\
\hline Teladorsagia circumcincta & $558.62(896.06)$ & $0-3500$ & 73 & 92.47 & $\mathrm{D}$ \\
\hline Haemonchus contortus & $69(288.29)$ & $0-1900$ & 46 & 7.2 & $\mathrm{D}$ \\
\hline Spiculopteragia spiculoptera morph spiculoptera & $2.44(8.23)$ & $0-40$ & 11 & 0.06 & CO-D \\
\hline Teladorsagia pinnata & $0.91(3.54)$ & $0-21$ & 9 & 0.018 & CO-D \\
\hline Teladorsagia trifurcata & $0.33(2.23)$ & $0-15$ & 2 & 0.016 & CO-D \\
\hline Trichostrongylus axei & $0.44(1.44)$ & $0-5$ & 8 & 0.008 & S \\
\hline Ostertagia ostertagi & $0.55(2.19)$ & $0-10$ & 6 & 0.008 & S \\
\hline Ostertagia leptospicularis & $0.44(1.79)$ & $0-10$ & 6 & 0.006 & S \\
\hline Spiculopteragia spiculoptera morph mathevossiani & $0.33(1.65)$ & $0-10$ & 4 & 0.003 & $S$ \\
\hline Ostertagia lyrata & $0.11(0.74)$ & $0-5$ & 2 & 0.0006 & S \\
\hline \multicolumn{6}{|l|}{ Small intestine } \\
\hline Trichostrongylus colubriformis & $444.31(1431.91)$ & $0-7200$ & 34 & 95.99 & $\mathrm{D}$ \\
\hline Nematodirus lanceolatus & $41.21(185.87)$ & $0-1000$ & 14 & 3.56 & $\mathrm{D}$ \\
\hline Nematodirus spathiger & $4.65(24.12)$ & $0-130$ & 7 & 0.2 & CO-D \\
\hline Bunostomum trigonocephalum & $1.83(5.94)$ & $0-30$ & 13 & 0.16 & CO-D \\
\hline Trichostrongylus capricola & $0.68(3.71)$ & $0-20$ & 3 & 0.014 & CO-D \\
\hline Nematodirus sp & $1.03(4.09)$ & $0-20$ & 7 & 0.04 & CO-D \\
\hline Nematodirus filicollis & $0.17(0.93)$ & $0-5$ & 7 & 0.007 & S \\
\hline Trichostrongylus vitrinus & $0.17(0.93)$ & $0-5$ & 3 & 0.003 & S \\
\hline Cooperia pectinata & $0.17(0.93)$ & $0-5$ & 3 & 0.003 & $S$ \\
\hline Strongyloides papillosus & $0.17(0.93)$ & $0-5$ & 3 & 0.003 & S \\
\hline \multicolumn{6}{|l|}{ Large intestine } \\
\hline Skrjabinema caprae & $1059.34(1321.72)$ & $0-6244$ & 95 & 89.03 & D \\
\hline Oesophagostomum venulosum & $50.92(73.22)$ & $0-275$ & 58 & 2.61 & $\mathrm{D}$ \\
\hline Chabertia ovina & $2.42(5.88)$ & $0-20$ & 21 & 0.04 & CO-D \\
\hline Trichuris ovis & $4.18(20.16)$ & $0-123$ & 11 & 0.039 & CO-D \\
\hline \multicolumn{6}{|l|}{ Total adult nematodes } \\
\hline Abomasum & $1370.08(1999.53)$ & $0-8165$ & 80 & & \\
\hline Small intestine & $1870.17(4146.71)$ & 0-19580 & 78 & & \\
\hline Large intestine & 2862.68 (3409.54) & $0-16337$ & 97 & & \\
\hline
\end{tabular}

${ }^{\circ} \mathrm{SD}=$ standard deviation.

${ }^{\S}$ Based on importance values helminth species were classified into categories; Dominant (D), species strongly characteristic of the community (I > 1.0), Codominant (CO-D) species contributing significantly to the community $(0.01<1<1.0)$, Subordinate species occurring infrequently, they do not contribute significantly to the community $(0<1<0.01)$.

Skrjabinema caprae and Oesophagostomum venulosum had the highest epidemiological parameters in the large intestine (Table 5). All sections of the gastrointestinal tract had high mean worm burdens, varying from 1370.08 to 2862.68 nematodes.

\section{Discussion}

The questionnaire indicated that the anthelmintic classes BZ and ML were used against GINs in Northern Italy and the FECRTs performed in accordance with WAAVP guidelines demonstrated that AR involved all two anthelmintic classes, with an overall prevalence of 33.33\% (5/15 flocks selected for AR testing). Resistance and suspected resistance was found in $40 \%(4 / 10)$ of the flocks selected for AR testing that were treated with BZs, while $20 \%(1 / 5)$ of the flocks treated with MLs had resistant GINs. The absence of L3 in the post-treatment coproculture from the flock with suspected resistance to OFZ, however, did not permit an accurate assessment of sensitivity to this drug. Excluding this flock would lower the percentage of flocks 
presenting AR to BZs to $30 \%(3 / 10)$ and the overall prevalence of AR resistance to $26.67 \%$ (4/15).

Very little data is available on AR on Italian goat farms. Resistance to BZs in Tr. colubriformis was recently demonstrated in southern Italy [24]. A generic resistance to BZs was reported by Genchi et al. [8], and AR has been reported in Italian sheep $[8,25,26]$. The presence of AR in goats throughout Europe is extremely variable, probably because several factors affect the development of resistance in GINs. Chartier et al. [27] found that AR to BZs was present in $100 \%(15 / 15)$ of tested flocks in western France, and a recent Norwegian survey detected AR in $7.69 \%(1 / 13)$ of tested flocks, suggesting that AR in Norway was only beginning [28]. AR has been detected at low frequencies in other European countries such as Sweden [29], Germany [30] and Slovakia [31]. BZs are the class of anthelmintic involved in most cases of AR [27,28,32].

AR to BZs in Northern Italy also appears to be more widespread than AR to MLs; this difference is probably due to the long-term use of BZs and the lack of rotation with other drugs on dairy-goat farms in this region. The isolation of L3 from post-treatment coprocultures from flocks with resistance to BZs indicated that only the Teladorsagia/Trichostrongylus group was resistant to this anthelmintic class. Reports of AR to ML on European goat farms are rare. AR in Teladorsagia, Trichostrongylus and Haemonchus has been reported in Denmark, Switzerland, Germany and the UK $[30,33,34]$. The L3 isolated from the T2 coproculture of flock 15 of our study, which were classed as resistant to EPM, were Teladorsagia/Trichostrongylus and Haemonchus. The T1 and T2 coprocultures from this flock showed that AR probably involved primarily Teladorsagia/Trichostrongylus. Haemonchus L3 were the most abundant (39\%) in T1 coprocultures, followed by Teladorsagia/Trichostrongylus L3 (32\%), while the proportion was inverted in T2 coprocultures (75\% Teladorsagia/ Trichostrongylus L3 and 25\% Haemonchus L3). Nevertheless, AR to EPM in flock 15 appeared to involve both Teladorsagia/Trichostrongylus and Haemonchus. Even though AR to EPM in goats had already been described in Switzerland and Germany, the results for this flock were quite unexpected. EPM is only registered for use in cattle in Italy, and the questionnaire indicated that its extra-label use occurred in only $0.91 \%$ (1/110) of Northern Italy farms. Flock 15 had never been treated with EPM, but the goats had been dewormed once a year for four years with IVM at the dose rate indicated for sheep. This practice in flock 15 may have caused the appearance of AR to the subclass of avermectins or to the entire ML anthelmintic class, despite the low frequency of treatment. The development of AR to the entire ML anthelmintic class (so also to MOX) due to the repeated use of ivermectin is reasonably still uncommon in goats; a treatment with
MOX in goats that failed against IVM-resistant Ostertagia (Teladorsagia) species was described by Leathwick [35] in New Zealand, and the GINs of a goat flock described by Scheuerle et al. [30] were resistant to EPM but still sensitive to MOX. The efficacy of MOX against GINs should be evaluated in flock 15, and generally on goat farms with verified AR to avermectins, because resistance to milbemycins differs from that to avermectins [36]. MOX, if effective, could be used to prevent the development of AR to milbemycins.

The questionnaire submitted to goat farmers of Northern Italy indicated that the annual number of treatments is very low respect to other countries [4,37]. In fact, the farmer answers showed that treatments against GINs were performed once annually in $73.63 \%$ of the flocks and less than once annually in $20.00 \%$ of the flocks. The low frequencies of treatments in Lombardy probably did not prevent the appearance of AR in GINs, as also suggested by Chartier et al. [38]. Moreover, the questionnaire revealed that errors in dose rates were common. First of all, the majority of farmers $(89.81 \%)$ declared to treat their goats with a dose rates for sheep and in all farms visual weight estimate was used. As a consequence, underdosing could result and selection of anthelminthic resistant worms was made easy. According to several authors, this event occurs more frequently in goats drenched with BZs as the bioavailability of the drugs is low than in sheep $[4,39,40]$. In addition, BZs, resulting in this study implicated in AR, were the most used drugs in Northern Italy and the alternation of anthelminthic families was not performed in any farms. Otherwise, very few drugs against GINs are registered in Italy for goats (6) at the same dose rate for sheep and they are not allowed in lactating goats (2 MLs, 1 levamisole/oxyclozanide) or a withdrawal time ( $\min 3$-max 9 days) is required (1 BZs, 1 proBZs, 1 morantel). It follows that the alternation of anthelminthic families to prevent AR as suggested is very difficult in Northern Italy [39]. Finally, the questionnaire survey showed poor drench practices widespread among goat farmers that probably generated the AR detected in GINs. However, it should be further considered that the control practice against GINs in goat flocks adopted by farmers in Northern Italy are not effective enough to improve the productivity in milking goats [39]. In fact, in this area the treatments are usually done in autumn-early winter; at this time treatments are less useful to prevent both the development of the disease and the contamination of pasture by nematode eggs being previously demonstrated that highest fecal egg counts in goats from Northern Italy occurred mainly in summer [6].

The survey on the composition of gastrointestinal helminthofaunas by the necroscopy of goats showed that Te. circumcincta, H. contortus, Tr. colubriformis, Sk. caprae and Oesophagostomum venulosum. were the most abundant and prevalent species of the gastrointestinal tract. Most of 
the species were previously reported in naturally infected goats in Northern Italy but $N$. lanceolatus is described for the first time in Italian goats [41,42]. According to Rossi [19], N. lanceolatus, placed in synonymy with $N$. oiratianus by Samson [43], showed distinctive features of spicul tips, bursal rays and lateral lobes of the caudal bursa. Some of the recorded helminths can also infect wild ruminants. For example, Sp. spiculoptera morph spiculoptera, Sp. spiculoptera morph mathevossiani and Os. leptospicularis are common parasites in Cervus elaphus and Capreolus capreolus [44], and Te. circumcincta is one of the most dominant species in the Alpine chamois, Rupicapra rupicapra $[41,44]$. The host distributions of these parasites suggest possible interactions between goats and wild ruminants. Similar interactions probably also occur in domestic species: goats and sheep share numerous gastrointestinal parasites (e.g. H. contortus), and the presence of Os. ostertagi in goats is probably due to its presence in cattle in the same pasture zones. Further, the analysis of helminthic community structure shows that these species, particularly Sp. spiculoptera morph spiculoptera, give an important contribution to composition of the community even if they have been classified into the categories of codominant or subordinate species by the importance values. In addition, the detection of a few species typical of cervids emphasizes that the goats may incur other parasitic risks resulting from interaction with these hosts on pastures [45]. Overall, a high number of helminth species is found than previous studies [46]. In this respect, it should be noted that the helminthofauna of a few goats from semiextensive farms sampled in this survey shows a scarce number of helminth species and appears dominated by Te. circumcincta. It may result from the few ecological niches offered by that environment to parasites life cycle rather the frequent use of anthelminthics [33,47]. By quantitative analysis, Te. circumcincta and Tr. colubriformis showed both high prevalence and worm burden in agreement especially with data of Chartier and Reche [46] but disagree with those of Domke et al. [48] that in goats from Norway found very low prevalence and abundance of Tr. colubriformis. As suggested by the authors, it may depend on the scarce ability to overwintering on pastures by this parasite. Further, $H$. contortus showed higher prevalence rates than has been previously found in goats from the same area or from different areas with temperate climate [41,46,49]. This parasite is especially frequent in dry areas where higher worm burden are also recorded; however, $H$. contortus has a wide distribution being also found in regions characterized by a very severe climate due its ability to survive inside the hosts [42,49-51]. At last, the presence of high worm burden of $S k$. caprae in the large intestine is remarkable; this parasite is generally considered with a very low pathogenicity but it can cause in dairy goats restlessness, itching and lesions in the perianal region [52]. In addition, all sector of gastrointestinal tract showed high worm burdens similar to those recorded in previous surveys as in goats from dry areas of Central Spain or Central and northern Greece [40,49]. These finding coupled with the high prevalence values ranging from $80 \%$ to $97 \%$ of goats with abomasal and intestinal infection respectively demonstrate that the GINs influence is very important in the surveyed area of Northern Italy including a few pastures with alpine features where despite the climatic conditions could be hard the GINs life cycle don't seem undergo any interruption. The present study provides sufficient data to make a picture of GINs infection in goat farms in Northern Italy by qualitative and quantitative point of view and based on these finding the risk posed by GINs infection on dairy goats raised in Northern Italy seems quite high.

\section{Conclusions}

The established presence of AR in 30\% of the tested flocks in Northern Italy suggests that strategies to prevent the development of AR should be widely adopted in this region. The answers to questionnaire show that farmers and practitioners should be firstly educated about the importance of using the correct dose rates in goats and about the rotation of different anthelmintic classes, because AR can develop even at low frequencies of treatment. The management of resistance on the farms presenting AR should include the use of targeted selective treatments to sustain susceptible GINs population in refugia [53]. The questionnaire survey further provide some information on the practices adopted to control GINs in dairy goats that could be useful to improve the treatments against GINs in Northern Italy. However, the results obtained during the survey showed the presence of highly pathogenic GINs, high worm burden in all sector of gastrointestinal tract and high prevalence values. These data also coupled with a few published reports demonstrating some changes on abundance, seasonality and spatial spread of GINs in the last years probably related to climate change [54] suggested that improved diagnosis and active surveillance of GINs infection should be wanted to allow a suitable control of GINs and improve host production. Furthermore, the knowledge of the composition of gastrointestinal helminthofauna and of the epidemiological parameters is also essential to reach this important objective and control the AR.

\section{Competing interests}

The authors declare that they have no competing interests.

\section{Authors' contributions}

The study idea was conceived by SAZ and MTM. ADC and MV participated in the design of the study; ADC helped administering the questionnaire. SAZ and AG participated in the acquisition of the laboratory data. SAZ and MTM carried out the statistical analysis. Data interpretation was done by all authors. SAZ, MTM and MV drafted the manuscript. All authors contributed to the critical revision of the manuscript for important intellectual content and have seen and approved the final draft. 


\section{Acknowledgements}

The authors thank the COST Action FA0805 (CAPARA) and all veterinary practitioners and SATA technicians of regional breeder association of Lombardy who have helped in our on-going research project.

\section{Author details}

${ }^{1}$ Department of Veterinary Science and Public Health, Università degli Studi di Milano, Milan, Italy. ${ }^{2}$ Parasitological Institute of the Slovak Academy of Science, Košice, Slovak Republic.

Received: 6 December 2013 Accepted: 6 May 2014

Published: 19 May 2014

\section{References}

1. van Houtert MF, Sykes AR: Implications of nutrition for the ability of ruminants to withstand gastrointestinal nematode infections. Int J Parasitol 2010, 26:1151-1167.

2. Waller PJ: Sustainable helminth control of ruminants in developing countries. Vet Parasitol 1997, 71:195-207.

3. Hoste H, Sotiraki S, Landau SY, Jackson F, Beveridge I: Goat-Nematode interactions: think differently. Trends Parasitol 2010, 26:376-381.

4. Domke AVM, Chartier C, Gjerde B, Leine N, Vatn S, Østeras O, Stuen S: Worm control practice in Norwegian sheep and goat flocks. Acta Vet Scand 2011, 53:29.

5. Waller PJ: The development of anthelminthic resistance in ruminant livestock. Acta Trop 1994, 56:233-243.

6. Di Cerbo AR, Manfredi MT, Zanzani S, Stradiotto K: Gastrointestinal infection in goat farms in Lombardy (Northern Italy): analysis on community and spatial distribution of parasites. Small Rum Res 2010, 88:102-112.

7. Manfredi MT, Di Cerbo AR, Zanzani S, Stradiotto K: Breeding management in goat farms of Lombardy, Northern Italy: riskfactors connected to gastrointestinal parasites. Small Rum Res 2010, 88:113-118.

8. Genchi C, Traldi G, Di Sacco B, Tassi B: Anthelmintic Resistant Nematodes in Farms Animals in Italy. In Anthelmintic Resistance in Nematodes of Farm Animals. Edited by Coles GC, Borgsteede FHM, Geerts S. Brussels: European Commission, Agriculture; 1993:107-113.

9. Ministry of Agriculture, Fisheries and Food: Manual of Veterinary Parasitological Laboratory Techniques. 3rd edition. London: Her Majesty's Stationary Office (HMSO); 1986.

10. Raynaud JP: Étude de l'efficacité d'une technique de coproscopie quantitative pour le diagnostic de routine et le contrôle des infestations parasitaires des bovins, ovins, équins et porcins. Ann Parasit Hum Comp 1970, 45:321-342.

11. Coles GC, Bauer C, Borgsteede FHM, Geerts S, Klei TR, Taylor MA, Waller PJ: World association for the Advancement of Veterinary Parasitology (W.A.A.V. P.): methods for the detection of anthelmintic resistance in nematodes of veterinary importance. Vet Parasitol 1992, 44:35-44.

12. Coles GC, Jackson F, Pomroy WE, Prichard RK, Von Samson-Himmelstjerna G, Silvestre A, Taylor MA, Vercruysse J: The detection of anthelmintic resistance in nematodes of veterinary importance. Vet Parasitol 2006, 136:167-185.

13. Cabaret J, Berrag B: Faecal egg count reduction test for assessing anthelmintic efficacy: average versus individually based estimations. Vet Parasitol 2004, 121:105-113.

14. van Wyk JA, Cabaret J, Michael LM: Morphological identification of nematode larvae of small ruminants and cattle simplified. Vet Parasito 2004, 119:277-306.

15. Drozdz J: Studies oh helminths and helminthiases in Cervidae. I. Revision of the subfamily Ostertaginae (Sarwar, 1956). Acta Parasitol 1965, 13:445-481.

16. Durette-Desset MC: Les Nematodirinae (Nematoda) chez les ruminants et chez les lagomorphes. Ann Parasit Hum Comp 1981, 54:313-329.

17. Gibbons LM: Revision of the African species of the genus Cooperia Ransom, 1907 (Nematoda, Trichostrongylidae). Syst Parasitol 1981, 2:219-252.

18. Lichtenfels JR, Pilitt PA, Lancaster MB: Systematics of the nematodes that cause ostertagiasis in cattle, sheep and goats in North America. Vet Parasitol 1988, 27:3-12.

19. Rossi P: Sur le genre Nematodirus Ransom, 1907. (Nematoda: Trichostrongyloidea). Ann Parasit Hum Comp 1983, 58:557-581.

20. Skrjabin KI: Key to Parasitic Nematodes. In Academy of Sciences of the URSS, 1952. 3rd edition. Jerusalem: Israel Program for Scientific Translation; 1961.
21. Durette-Desset MC: Sur la divisions generiques des Nematodes Ostertaginae (Trichostrongylidae). Ann Parasit Hum Comp 1982, 64:356-373.

22. Bush $A O$, Lafferty KD, Jeffrey ML, Shostak AW: Parasitology meets ecology on its own terms: Margolis et al. revisited. J Parasitol 1997, 83:575-583.

23. Thul JE, Forrester DJ, Abercrombie CL: Ecology of parasitic helminth of wood ducks, Air sponsa, in the Atlantic flyway. Proc Helminthol Soc Wash 1985, 52:297-310.

24. Cringoli G, Veneziano V, Rinaldi L, Sauvé C, Rubino R, Fedele V, Cabaret J: Resistance of trichostrongyles to benzimidazoles in Italy: a first report in a goat farm with multiple and repeated introductions. Parasitol Res 2007, 101:577-581.

25. Ambrosini F: The resistance of Trichostrongylids to anthelminthics in sheep. JAEID 2000, 94:105-126.

26. Traversa D, Paoletti B, Otranto D, Miller J: First report of multiple drug resistance in trichostrongyles affecting sheep under field conditions in Italy. Parasitol Res 2007, 101:1713-1716.

27. Chartier C, Pors I, Hubert J, Rocheteau D, Benoit C, Bernard N: Prevalence of anthelmintic resistant nematodes in sheep and goats in western France. Small Ruminant Res 1998, 29:33-41.

28. Domke AVM, Chartier C, Gjerde B, Höglund J, Leine N, Vatn S, Stuen S: Prevalence of anthelmintic resistance in gastrointestinal nematodes of sheep and goats in Norway. Parasitol Res 2012, 111:185-193.

29. Hőglund J, Gustafsson K, Ljungstrőm BL, Engstrőm A, Donnan A, Skuce P: Anthelmintic resistance in Swedish sheep flocks based on a comparison of the results from the fecal egg count reduction test and resistant allele frequencies of the beta-tubulin gene. Vet Parasitol 2009, 161:60-68.

30. Scheuerle MC, Mahling M, Pfister K: Anthelmintic resistance of Haemonchus contortus in small ruminants in Switzerland and southern Germany. Wien Klin Wochenschr 2009, 121:46-49.

31. Varady M, Corba J, Cernaská D: A survey on anthelminthic resistance in nematode parasites of sheep in the Slovak Republic. Vet Parasito/ 2006 135:39-45.

32. Hong C, Hunt KR, Coles GC: Occurrence of anthelmintic resistant nematodes on sheep farms in England and goat farms in England and Wales. Vet Parasitol 1996, 139:83-86

33. Maingi N, Bjørn H, Thamsborg SM, Bøgh HO, Nansen P: A survey of anthelmintic resistance in nematode parasites of goats in Denmark. Vet Parasitol 1996, 66:53-66.

34. VLA Surveillance Report: Multiple anthelmintic resistance in goat nematodes. Vet Rec 2006, 158:357-36.

35. Leathwick DM: A case of moxidectin failing to control ivermectin resistant Ostertagia species in goats. Vet Rec 1995, 136:443-444.

36. Prichard R, Ménez C, Lespine A: Moxidectin and the avermectins: consanguinity but not identity. Int J Parasitol Drugs Drug Res 2012, 2:134-153.

37. Maingi N, Bjørn H, Thamsborg SM, Dangolla A, Kyvsgaard NC: Worm control practices on sheep fams in Denmark and implications for the develpment of anthelmintc resistance. Vet Parasitol 1996, 66:39-52.

38. Chartier C, Soubirac F, Pors I, Silvestre A, Hubert J, Couquet C, Cabaret J: Prevalence of anthelmintic resistance in gastrointestinal nematodes of dairy goats under extensive management conditions in southwestern France. J Helminthol 2001, 75:325-330.

39. Hoste H, Chartier C, Etter E, Goudeau C, Soubirac F, Lefrileux Y: A questionnaire survey on the practices adopted to control gastrointestinal nematode parasitism in dairy goat farms in France. Vet Res Comm 2000, 2000(24):459-469.

40. Papadopoulus E, Arsenos G, Sotiraki S, Deligiannis C, Lainas T, Zygoyiannis D: The epizootiology of gastrointestinal nematode parasite in Greek dairy breeds of sheep and goats. Small Rum Res 2003, 47:193-202.

41. Genchi C, Manfredi MT, Bossi A: Les infestations naturelles par les strongles digestifs sur les paturages de haute montagne: interaction entre la chèvre et le chamois. Les Colloques de I'INRA 1984, 28:502-505. Niort, France.

42. Torina A, Dara S, Marino AMF, Sparagano OAE, Vitale F, Reale S, Caracappa S: Study of gastrointestinal nematodes in Sicilian sheep and goats. Ann N Y Acad Sci 2004, 1026:187-194.

43. Samson KS: The sinonimy of the ruminant parasites Nematodirus oiratianus Raevskaia, 1920 and Nematodirus lanceolatus Ault, 1944. Proc Helminth Soc Wash 1968, 35:52-53.

44. Zaffaroni E, Manfredi MT, Citterio C, Sala M, Piccolo G, Lanfranchi P: Host specificity of abomasal nematodes in free ranging alpine ruminants. Vet Parasitol 2000, 90:221-230. 
45. Alberti EG, Gioia G, Sironi G, Zanzani S, Riccaboni P, Magrini M, Manfredi MT: Elaphostrongylus cervi in a population of red deer (Cervus elaphus) and evidence of cerebrospinal nematodiasis in small ruminants in the province of Varese, Italy. J Helminthol 2011, 85:313-318.

46. Chartier C, Reche B: Gastrointestinal helminthes and lungworms of French dairy goats: prevalence and geographical distribution in Poitou-Charentes. Vet Res Comm 1992, 16:327-355.

47. Manfredi MT: Biologia dei nematodi gastrointestinali dei ruminanti. Parassitologia 2006, 48:397-401.

48. Domke AVM, Chartier C, Gjerde B, Leine N, Vatn S, Stuen S: Prevalence of gastrointestinal helminths, lungworms and liver fluke in sheep and goats in Norway. Vet Parasitol 2013, 194:40-48.

49. Valcárcel F, Garcia Romero C: Prevalence and seasonal pattern of caprine trichostrongyles in a dry area of central Spain. J Vet Med B 1999, 46:673-681.

50. Lindqvist A, Ljungström BL, Nilsson O, Waller PJ: The dynamics, prevalence and impact of nematode infections in organically raised sheep in Sweden. Acta Vet Scand 2001, 42:377-389.

51. Pino LA, Morales G, Aldana E, Perdomo L, Molina E: Caracterización microecológica de los nematodos parásitos de ovinos de zonas áridas de Venezuela. (Un nuevo criterio para el control). Rev lbér Parsitol 1986, 46:395-401.

52. Borgsteede FH, Dercksen DP: Coccidial and helminth infection in goats keept indoors in the Netherlands. Vet Parasitol 1996, 65:321-326.

53. Jackson F, Varady M, Bartley DJ: Managing anthelmintic resistance in goats. can we learn lessons from sheep? Small Ruminant Res 2012, 103:3-9.

54. van Dijk J, Sargison ND, Kenyon F, Skuce PJ: Climate change and infectious disease: helminthological challenges to farmed ruminants in temperate regions. Animal 2010, 4:377-392.

doi:10.1186/1746-6148-10-114

Cite this article as: Zanzani et al:: Gastrointestinal nematodes of dairy goats, anthelmintic resistance and practices of parasite control in Northern Italy. BMC Veterinary Research 2014 10:114

\section{Submit your next manuscript to BioMed Central and take full advantage of:}

- Convenient online submission

- Thorough peer review

- No space constraints or color figure charges

- Immediate publication on acceptance

- Inclusion in PubMed, CAS, Scopus and Google Scholar

- Research which is freely available for redistribution 